\title{
Modelling Age-Related Changes in the Pharmacokinetics of Risperidone and 9-Hydroxyrisperidone in Different CYP2D6 Phenotypes Using a Physiologically Based Pharmacokinetic Approach
}

\author{
Lisa Alina Kneller ${ }^{\prime} \cdot$ Georg Hempel ' (D) \\ Received: 11 December 2019 / Accepted: 19 May 2020/ Published online: 31 May 2020 \\ (C) The Author(s) 2020
}

\begin{abstract}
Purpose Dose-optimization strategies for risperidone are gaining in importance, especially in the elderly. Based on the genetic polymorphism of cytochrome P 450 (CYP) 2D6 genetically and age-related changes cause differences in the pharmacokinetics of risperidone and 9-hydroxyrisperidone. The goal of the study was to develop physiologically based pharmacokinetic (PBPK) models for the elderly aged 65+ years. Additionally, CYP2D6 phenotyping using metabolic ratio were applied and different pharmacokinetic parameter for different age classes predicted.
\end{abstract}

Methods Plasma concentrations of risperidone and 9hydroxyrisperidone were used to phenotype 17 geriatric inpatients treated under naturalistic conditions. For this purpose, PBPK models were developed to examine age-related changes in the pharmacokinetics between CYP2D6 extensive metabolizer, intermediate metabolizer, poor metabolizer, $(\mathrm{PM})$ and ultra-rapid metabolizer.

Results PBPK-based metabolic ratio was able to predict different CYP2D6 phenotypes during steady-state. One inpatient was identified as a potential PM, showing a metabolic ratio of 3.39 . About $88.2 \%$ of all predicted plasma concentrations of the inpatients were within the 2-fold error range. Overall, age-related changes of the pharmacokinetics in the elderly were mainly observed in Cmax and AUC. Comparing a population of young adults with the oldest-old, Cmax of

Georg Hempel

georg.hempel@uni-muenster.de

Lisa Alina Kneller

lisa.kneller@uni-muenster.de

Institute of Pharmaceutical and Medical Chemistry, Clinical Pharmacy, University of Münster, Corrensstr. 48, 48 I 49 Münster, Germany risperidone increased with $24-44 \%$ and for 9 hydroxyrisperidone with $35-37 \%$.

Conclusions Metabolic ratio combined with PBPK modelling can provide a powerful tool to identify potential CYP2D6 PM during therapeutic drug monitoring. Based on genetic, anatomical and physiological changes during aging, PBPK models ultimately support decision-making regarding dose-optimization strategies to ensure the best therapy for each patient over the age of 65 years.

KEY WORDS CYP2D6 polymorphism · elderly · PBPK . pharmacokinetics $\cdot$ risperidone

$\begin{array}{ll}\text { ABBREVIATIONS } \\ \text { ADR } & \text { Adverse drug reactions } \\ \text { AUC } & \text { Area under the systemic drug concentration-time } \\ & \text { profile } \\ C_{\max } & \text { Maximum plasma concentration of the drug } \\ \text { CYP } & \text { Cytochrome P450 } \\ \text { EM } & \text { Extensive metabolizer } \\ \text { IM } & \text { Intermediate metabolizer } \\ \text { MAPE } & \text { Mean absolute prediction error } \\ \text { MPE } & \text { Mean prediction error } \\ \text { PBPK } & \text { Physiologically based pharmacokinetic } \\ \text { PD } & \text { Pharmacodynamic } \\ \text { PE } & \text { Prediction error } \\ \text { PK } & \text { Pharmacokinetic } \\ \text { PM } & \text { Poor metabolizer } \\ \text { TDM } & \text { Therapeutic drug monitoring } \\ t_{\text {max }} & \text { Time it takes until the drug reached } \mathrm{C}_{\max } \\ \mathrm{t}_{1 / 2} & \text { Half-life time } \\ \text { UM } & \text { Ultra-rapid metabolizer }\end{array}$




\section{INTRODUCTION}

The world's population is aging. In Germany, the number of people aged 65 years and above was reported at 17.8 million $(21 \%)$ in 2018, exhibiting an upward trend $(1,2)$. Thereby, the age-related comorbidities such as psychotic disorders will rise and the craving for individual treatment in geriatric patients is gaining in importance. One potential treatment option in geriatric patients is risperidone, an atypical antipsychotic. In Norway, $30 \%$ of the overall number of risperidone-treated patients are 65 years or older (3). Despite the growing population of elderly individuals, they are often omitted from clinical trials (4). Since psychotropic agents often exhibit great inter-individual variability, only little is known about the impact of aging on the pharmacokinetics (PK) of risperidone and its active metabolite 9-hydroxyrisperidone.

In general, advanced age is characterized by anatomical, physiological, and biochemical changes potentially influencing drug relevant PK. Besides decreased kidney weight (5), reduced renal blood flow (6), reduced glomerular filtration rate (7), reductions in liver volume and blood flow are also affected (8-10). Based on the age-related decline in liver volume, geriatric patients are potentially at a higher risk to adverse drug reactions (ADR) because of their reduced drug metabolizing capacity reserve (11). In contrast to that, Shulman and Ozdemir supposed that cytochrome P450 (CYP) 2D6 activity, which represents the main enzymatic pathway for the antipsychotic agent (12-14), does not change with age (15). Although no enzymatic change was observed, the PK of the active moiety (sum of risperidone and 9hydroxyrisperidone) potentially vary in the different types of CYP2D6 metabolizers because of age-related changes. In relation to this, a population pharmacokinetic analysis identified age as a significant covariate on the 9-hydroxyrisperidone clearance (16). However, the therapeutic reference range of the active moiety amounts to $20-60 \mathrm{ng} / \mathrm{mL}$ published by Hiemke et al. (17). While the most recommended dose in the treatment of schizophrenia in adult patients amounts to $6 \mathrm{mg} /$ day (18), dose reductions should be taken into account for the elderly (19). Therefore, a unifying concept to determine which type of CYP2D6 metabolizer might be more at risk of $\mathrm{PK}$ adverse effects would be a benefit due to a greater heterogeneity in the elderly compared to the young adults (11).

Though risperidone metabolism is regulated by the genetic polymorphism of CIP2D 6 , only little is known about correct dosing strategies in the different types of CYP2D6 metabolizers. Based on $>100$ allelic variants of the CYP2D 6 genotype, four different phenotypes have been proposed $(20,21)$ : extensive metabolizer (EM), intermediate metabolizer (IM), poor metabolizer (PM), and ultra-rapid metabolizer (UM). To ensure the best therapy for each patient, dose adjustment for genetically caused differences in the plasma concentrations must be considered especially in the elderly to reduce ADR and discontinuations due to ADR in different CYP2D6 phenotypes. So, the aim of the current investigation was to extrapolate a previously published physiologically based pharmacokinetic (PBPK) model to analyze the impact of agerelated changes in different types of CYP2D6 metabolizers on the PK of risperidone and 9-hydroxyrisperidone (22). The second aim was to apply calculated risperidone/9hydroxyrisperidone ratio to classify geriatric patients in different CYP2D6 metabolizers using a PBPK approach. Lastly, we analyzed changes in the PK between the elderly and young adults to finally optimize standard dosage regimes in different CYP2D6 metabolizers. To our knowledge, this is the first study examining the age-related effects of CYP2D6 phenotype-related physiological alterations on the PK of risperidone using a PBPK approach.

\section{MATERIALS AND METHODS}

\section{Physiologically Based Pharmacokinetic Modelling}

A previously published whole-body PBPK model for risperidone and 9-hydroxyrisperidone was used (22). The modelling was performed using $\mathrm{PK}-\mathrm{Sim}{ }^{\circledR} / \mathrm{MoBi}{ }^{\circledR}$ version 7.3 .0 as part of the Open System Pharmacology Suite (23). This package contains a freely available whole-body PBPK simulation software, allowing the prediction of PK, especially for drugs in humans, as well as in several mammalian organisms (23). With the help of PBPK modelling it is possible to run virtual clinical trials of specific subpopulations to overcome sparse clinical data. For a detailed description of the generic model structure, consisting of 17 different compartments, and the input/output parameters, please refer to the user software manual (24), Willmann et al. (25) or Kuepfer et al. (26).

\section{Model Extrapolation}

The published PBPK models were utilized to predict agerelated changes in PK values of risperidone and 9hydroxyrisperidone from young adults (18-35 years) to the elderly aged $65+$ years. For model extrapolation the modelling software considered age-dependent anatomical and physiological changes, e.g. weight of the organs and tissues including blood content, blood flow rates, body composition, etc. (27). Age-related changes in CYP2D6 activity were not implemented, as there does not appear to be an age-related decline in the activity of this enzyme in the elderly $(15,28)$. However, significant interactions can occur from concomitant medication, either competitively or noncompetitively inhibiting CIP2D6 (28). Consequently, no compound-related modifications were conducted for model extrapolation. 


\section{Model Verification}

\section{Study Data}

All PBPK models were verified in the elderly using published clinical data of 20 geriatric inpatients aged 55 years of age or older, admitted to the inpatient programs of the Western Psychiatric Institute and Clinic (3811 O'Hara Street, Pittsburgh, PAP 15213) between November 1996 and March 1998 (29). All patients were identified through daily reviews of pharmacy records, prescribed risperidone and treated under naturalistic conditions. A specification regarding the ethnic origin of the inpatients and the type of CYP2D6 metabolizer was not made.

\section{Data Implementation}

For model verification, only the elderly inpatients (aged 65+ years) were included into PBPK simulation. Thereby, a total of 17 geriatrics and their corresponding 17 plasma samples were implemented. Calculated creatinine clearance of the subjects were not considered in modelling, as urine collection took place over a period of $8 \mathrm{~h}$. For a correct quantitative analysis, it is necessary to measure the total amount of solutes excreted in a 24-h period, because many solutes exhibits diurnal variations (30). For modelling, all geriatric inpatients were classified as European, as no information of the ethnic origin was provided and the value of age for white Americans must be less than or equal to 81 years, stated by the software (24). Detailed demographic data and patient characteristics are summarized in Table 1.

\section{Phenotyping Using Metabolic Ratio}

All geriatric inpatients were individually classified into the different types of CYP2D6 metabolizer, according to calculated risperidone/9-hydroxyrisperidone ratio (also called metabolic ratio), which is a marker for CYP2D6 activity. Here, the increase in the number of active CYP2D6 alleles indicates a decrease risperidone/9-hydroxyrisperidone ratio. The following mean values were used for phenotyping, taking timedependency of the ratio into account: $0.16(\mathrm{UM}), 0.27(\mathrm{EM})$, 0.72 (IM), and 5.00 (PM) (22). The individual classification of the 17 geriatric inpatients was based on the distance to the respective mean ratio. A detailed overview about metabolic ratio and its predicted phenotype is provided in Table 1 .

\section{Modelling and Simulation}

For model verification, 17 different simulations were built, representing each geriatric inpatient. Here, the individual predicted CYP2D6 phenotype was taken into account. Furthermore, all generated PBPK individuals were in agreement with the corresponding patient characteristics in terms of gender, age and weight (Table 1). Patient-specific daily doses of risperidone $(0.5-3 \mathrm{mg} /$ day) were considered in each simulation (Table 1). To ensure a steady-state condition, modelling was carried out over a time frame of 6 days $(144 \mathrm{~h})$ and $120 \mathrm{~h}$ was set as sampling relevant dosing time point. All risperidone's and 9-hydroxyrisperidone's plasma samples of Maxwell et al. were used as observed data in modelling and simulation (Table 1). Maxwell et al. reported that plasma samples were obtained in the morning 9-13 $\mathrm{h}$ after the last risperidone dose (in one not defined inpatient $15.5 \mathrm{~h}$ ). Since no precise patient-individual sampling time points are available, time points (129-135.5 h) were estimated visually by comparing the measured with the predicted plasma concentrations horizontally. A visual comparison was also performed regarding dosing interval (once a day or bi-daily). Simulations were defined as being successful, if the predicted plasma concentration-time profiles of risperidone and 9hydroxyrisperidone were within the 0.5 - to 2 -fold interval of the observed concentration of each individual inpatient.

\section{Prediction of the Pharmacokinetics}

After the successful extrapolation and verification of PBPK models, they were utilized to predict age-related changes in different PK values from young adults (18-35 years) to the elderly aged $65+$ years. All elderly patients were further subdivided into the following classes: young-olds (65-74 years), medium-olds (75-84 years), and oldest-old (85-100 years) according to the Recommendations on Definition and Classification of Age provided by the National Statistical Standards in November 2016 (31). No adjustment to the PBPK models were done when extrapolating simulations to the different age-classes. Simulations were carried out with the aid of a computer-assisted Monte-Carlo method on populations consisting of 1000 virtual individuals (proportion of women: 0.5$)$ over a time period of 1 week $(168 \mathrm{~h})$ including risperidone and 9-hydroxyrisperidone. Steady-state simulations were performed starting with $0.5 \mathrm{mg}$ twice a day for 1 day, resulting in a dose increase of up to $1 \mathrm{mg}$ twice a day (2 mg/day). The different types of CYP2D6 metabolizers (EM, IM, PM, and UM) were considered separately.

\section{Statistical Analysis}

The evaluation of the extrapolated PBPK models was carried out in accordance with the Guideline on the Qualification and Reporting of Physiologically Based Pharmacokinetic Modelling and Simulation (32). Different PK values, such as the median area under the systemic drug concentration-time profile (AUC), maximum plasma concentration of the drug $\left(\mathrm{C}_{\max }\right)$, time it takes until the drug reached the $\mathrm{C}_{\max }\left(\mathrm{t}_{\max }\right)$, as 
Table I Overview of enrolled geriatric inpatients characteristics for PBPK modelling. EM: extensive metabolizer; f: female; IM: intermediate metabolizer; m: male; PM: poor metabolizer; UM: ultra-rapid metabolizer

\begin{tabular}{|c|c|c|c|c|c|c|c|c|}
\hline Patient & Gender & Age (years) & Weight (kg) & $\begin{array}{l}\text { Dose } \\
\text { (mg/day) }\end{array}$ & $\begin{array}{l}\text { Risperidone } \\
\text { concentration }(\mu \mathrm{g} / \mathrm{L})\end{array}$ & $\begin{array}{l}\text { 9-hydroxy-risperidone } \\
\text { concentration }(\mu g / L)\end{array}$ & $\begin{array}{l}\text { Risperidone/9- } \\
\text { hydroxyrisperidone Ratio }\end{array}$ & $\begin{array}{l}\text { Predicted } \\
\text { Phenotype }\end{array}$ \\
\hline 4 & $f$ & 69 & 45.8 & 1.00 & 6.56 & 6.54 & 1.00 & IM \\
\hline 5 & $f$ & 69 & 47.2 & 1.50 & 0.52 & 4.38 & 0.12 & UM \\
\hline 6 & $f$ & 73 & 76.7 & 1.00 & 4.51 & 5.09 & 0.89 & IM \\
\hline 7 & f & 73 & 89.4 & 0.75 & 0.60 & 7.80 & 0.08 & UM \\
\hline 8 & f & 77 & 55.3 & 0.50 & 1.99 & 4.01 & 0.50 & IM \\
\hline 9 & f & 78 & 62.1 & 3.00 & 1.38 & 5.12 & 0.27 & $E M$ \\
\hline 10 & $\mathrm{~m}$ & 79 & 88.0 & 1.00 & 0.32 & 5.38 & 0.06 & UM \\
\hline 11 & $\mathrm{~m}$ & 79 & 77.6 & 2.50 & 1.40 & 15.8 & 0.09 & UM \\
\hline 12 & f & 80 & 59.0 & 0.50 & 2.66 & 4.84 & 0.55 & $\mathrm{IM}$ \\
\hline 13 & $\mathrm{~m}$ & 80 & 58.5 & 1.00 & 11.2 & 6.30 & 1.78 & $\mathrm{IM}$ \\
\hline 14 & $f$ & 81 & 69.9 & 2.00 & 2.04 & 13.0 & 0.16 & UM \\
\hline 15 & $f$ & 81 & 49.0 & 1.50 & 6.33 & 1.87 & 3.39 & PM \\
\hline 16 & $\mathrm{~m}$ & 82 & 63.1 & 1.00 & 2.03 & 9.67 & 0.21 & EM \\
\hline 17 & $f$ & 82 & 50.8 & 0.75 & 0.34 & 6.96 & 0.05 & UM \\
\hline 18 & $\mathrm{~m}$ & 86 & 69.9 & 1.00 & 22.3 & 24.8 & 0.90 & $\mathrm{IM}$ \\
\hline 19 & $\mathrm{~m}$ & 88 & 57.2 & 1.00 & 2.40 & 6.40 & 0.38 & $E M$ \\
\hline 20 & $f$ & 91 & 68.0 & 0.50 & 3.28 & 7.92 & 0.41 & EM \\
\hline
\end{tabular}

well as the terminal half-life time $\left(\mathrm{t}_{1 / 2}\right)$, were calculated by PK$\operatorname{Sim} \AA$.

The quality of PBPK model verification was analyzed using predicted versus observed data plots and weighted residuals versus observed plasma concentrations. To describe model accuracy and precision, prediction error (PE), mean prediction error (MPE) and mean absolute prediction error (MAPE) were calculated according to Eqs. 1-3.

$\mathrm{PE}[\%]=\frac{\text { predicted }- \text { observed }}{\text { observed }} \times 100$

$\operatorname{MPE}[\%]=\frac{1}{n} x \sum_{i=1}^{n} P E i$

$\operatorname{MAPE}[\%]=\frac{1}{n} x \sum_{i=1}^{n}|P E i|$

All statistical and graphical analytics were performed in $\mathrm{R}$ (version 3.4.2; R Foundation for Statistical Computing, Vienna, Austria) (33).

\section{RESULTS}

\section{CYP2D6 Phenotyping Using Metabolic Ratio}

Based on a previously developed risperidone/9hydroxyrisperidone ratio for each CYP2D6 phenotype, the ratio was applied to clinically observed data of 17 geriatric inpatients treated under naturalistic conditions to identify the individual type of CYP2D6 metabolizer (Table 1). Overall, ten geriatric inpatients show a non-reduced metabolic capacity for CYP2D6 (EM and UM) and six inpatients a reduced function (IM) whereas one of the 17 geriatric inpatients $(5.88 \%)$ was identified as PM, showing a plasma concentration of $6.33 \mu \mathrm{g} / \mathrm{L}$ for the parent drug compared to a value of $1.87 \mu \mathrm{g} / \mathrm{L}$ for the active metabolite. Thus, calculated metabolic ratio (risperidone/9-hydroxyrisperidone) amounts to 3.39 illustrating a higher metabolic ratio compared to the metabolic ratio of the other 16 inpatients (range: 0.05-1.78). An overview of all plasma concentration-time curve profiles is provided in Fig. 1.

\section{PBPK Model Application in the Elderly}

After PBPK model extrapolation to the elderly, the models accurately describe the plasma concentrations of the parent drug and its metabolite during steady-state condition in elderly adults aged $\geq 65$ years. Predicted plasma concentrations of risperidone and 9-hydroxyrisperidone were in close agreement to the observed clinical data of each individual, as can be seen by the individual plasma concentration-time curve profile of each geriatric inpatient (Fig. 1). 52.9\% of all predicted plasma concentrations were within the 1.25-fold error range and $88.2 \%$ were within the 2 -fold error range in the plot of predicted versus observed data (Fig. 2). A total of four (three risperidone and one 9-hydroxyrisperidone) plasma concentrations out of 34 samples $(11.8 \%)$ were outside of the 2- 

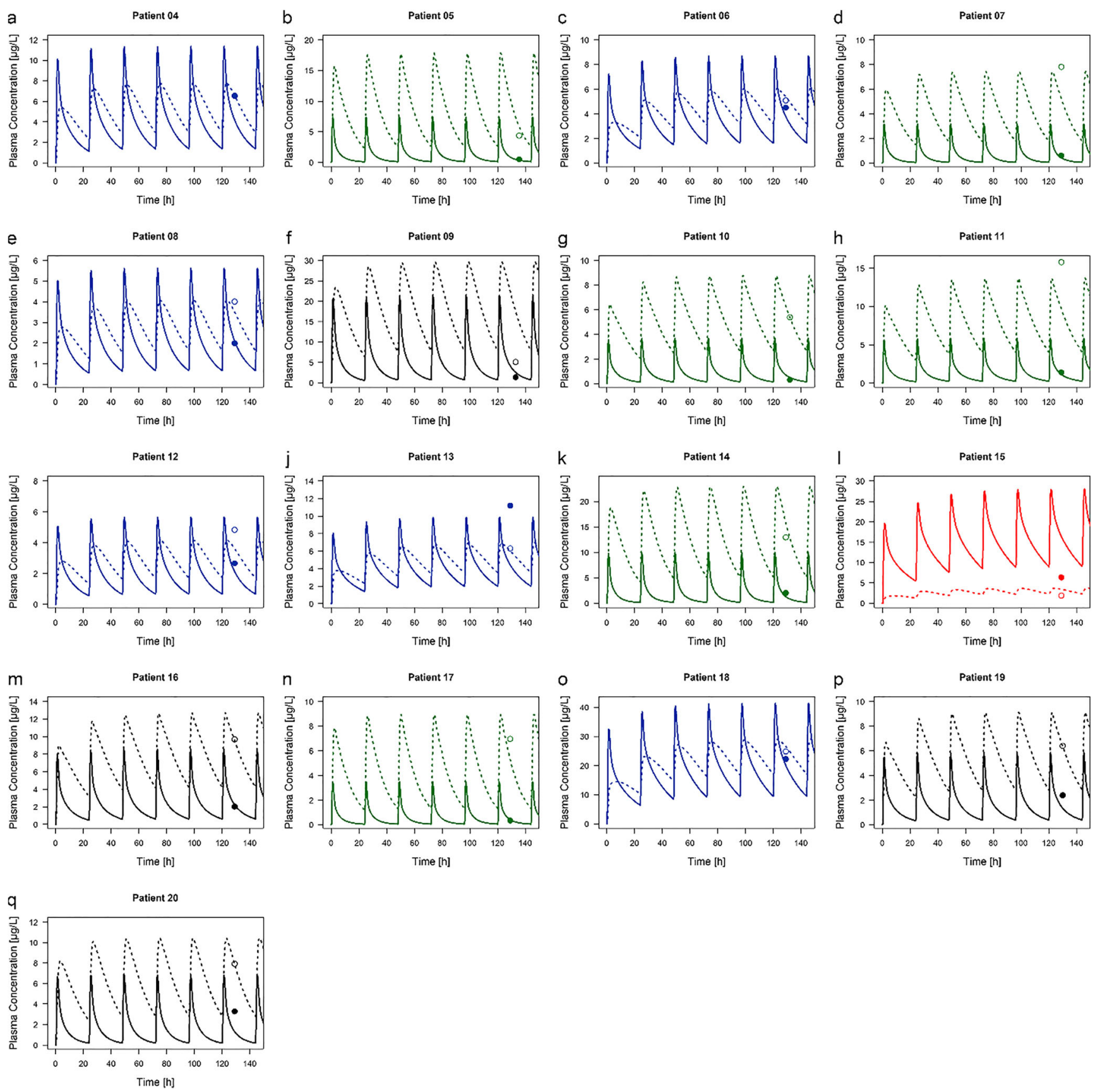

Fig. I a-q Plasma concentration- time curve profiles of risperidone and 9-hydroxyrisperidone. Solid lines indicate the mean prediction of risperidone. Dashed lines indicate the prediction of 9-hydroxyrisperidone. Circles indicate observed plasma concentrations. Black colors represent extensive metabolizers, blue colors intermediate metabolizers, red colors poor metabolizers and green colors ultra-rapid metabolizer

fold error range, indicating a possible influence of individual concomitant medication on the metabolizing enzymes CYP2D6 and CYP3A4. In accordance with this, the visual comparison of the plasma concentration-time curve profile of these inpatients show a deviation between the observed clinical data and the predicted values (Fig. 1). Except from those four geriatric inpatients the developed PBPK models show a high accuracy illustrated by a minimal bias (MPE range: $-43.8 \%$ to $56.7 \%$ for risperidone and $-38.6 \%$ to
$34.4 \%$ for 9-hydroxyrisperidone) and a good precision (MAPE range: $5.7 \%$ to $56.7 \%$ for risperidone and $0.3 \%$ to $38.6 \%$ for 9-hydroxyrisperidone). In contrast to that a higher bias and lower precision can be seen in the remaining four geriatric inpatients. Here the MPE amounts to a range of $-59.7 \%$ to $159.9 \%$ for risperidone and $-3.9 \%$ to $241.8 \%$ for 9-hydroxyrisperidone and the MAPE amounts to a range of $59.7 \%$ to $159.9 \%$ for risperidone and $0 \%$ to $241.8 \%$ for 9 hydroxyrisperidone, respectively (Table 2). In accordance 


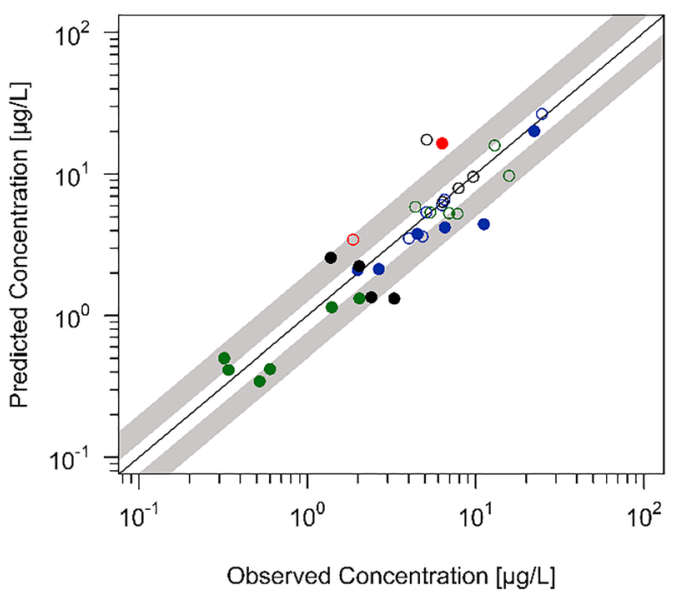

b

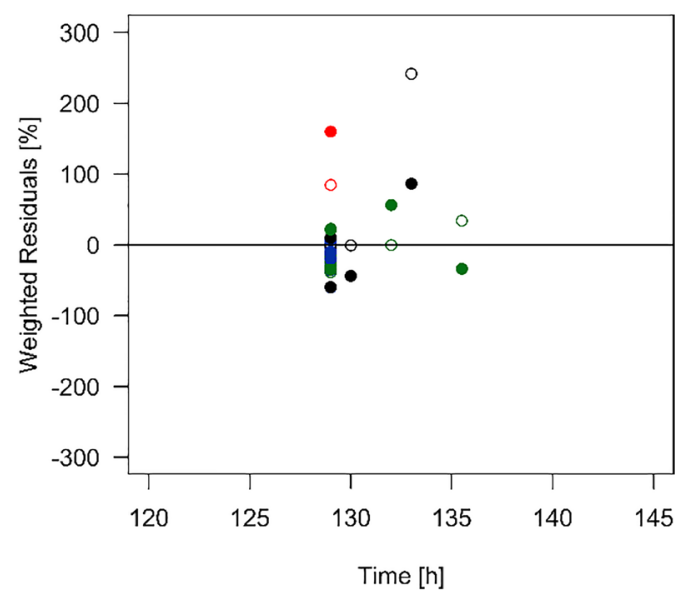

Fig. 2 a Plot of predicted versus observed data for model prediction of risperidone and 9-hydroxyrisperidone plasma concentrations in all 17 geriatric inpatients. The solid black line indicated the line of identity, filled (risperidone) and open (9-hydroxyrisperidone) circles indicate observed data. Black circles represent extensive metabolizers, blue circles intermediate metabolizers, red circles poor metabolizers and green circles ultra-rapid metabolizers. The white area represents the 1.25-fold error range and the grey area the 2-fold error range. b Weighted residuals versus observed risperidone and 9-hydroxyrisperidone concentrations for all 17 geriatric inpatients. The solid black line indicated the line of identity, filled (risperidone) and open (9-hydroxyrisperidone) circles indicate observed data. Black circles represent extensive metabolizers, blue circles intermediate metabolizers, red circles poor metabolizers and green circles ultra-rapid metabolizers

with the respective plasma concentration-time profiles of those four geriatric inpatients, the calculated MPE and MAPE suggesting a possible impact on the metabolism of risperidone, resulting in an over-prediction of the PK values especially of

Table 2 Calculated ratios and mean absolute prediction error (MAPE) for the prediction of plasma concentrations of risperidone and 9hydroxyrisperidone

\begin{tabular}{|c|c|c|c|c|}
\hline \multirow[t]{2}{*}{ Patient } & \multicolumn{2}{|l|}{ Risperidone } & \multicolumn{2}{|l|}{ 9-hydroxyrisperidone } \\
\hline & $\begin{array}{l}\text { predicted/observed } \\
\text { ratio }\end{array}$ & MAPE & $\begin{array}{l}\text { predicted/observed } \\
\text { ratio }\end{array}$ & MAPE \\
\hline 4 & 0.64 & 35.9 & 1.01 & 0.7 \\
\hline 5 & 0.66 & 33.7 & 1.34 & 34.4 \\
\hline 6 & 0.84 & 16.1 & 1.06 & 5.9 \\
\hline 7 & 0.70 & 29.8 & 0.67 & 32.7 \\
\hline 8 & 1.06 & 5.7 & 0.88 & 12.4 \\
\hline 9 & 1.86 & 86.1 & 3.42 & 241.8 \\
\hline 10 & 1.57 & 56.7 & 1.00 & 0.3 \\
\hline 11 & 0.82 & 18.3 & 0.61 & 38.6 \\
\hline 12 & 0.80 & 19.9 & 0.75 & 25.2 \\
\hline 13 & 0.40 & 60.3 & 0.96 & 3.9 \\
\hline 14 & 0.65 & 35.2 & 1.23 & 22.9 \\
\hline 15 & 2.60 & 159.9 & 1.84 & 84.4 \\
\hline 16 & 1.10 & 10.3 & 0.99 & 1.3 \\
\hline 17 & 1.22 & 21.9 & 0.76 & 23.7 \\
\hline 18 & 0.90 & 9.6 & 1.07 & 7.1 \\
\hline 19 & 0.56 & 43.8 & 0.99 & 0.6 \\
\hline 20 & 0.40 & 59.7 & 1.00 & 0.0 \\
\hline
\end{tabular}

the active metabolite. In addition, the plot of predicted versus observed data support these observations (Fig. 2).

\section{Age-Related Changes in the Pharmacokinetics}

The predicted $\mathrm{C}_{\max }$ of risperidone and 9-hydroxyrisperidone increased with age in all types of CYP2D6 metabolizer. Comparing a population of young adults with oldest-old, the $\mathrm{C}_{\max }$ during steady-state of risperidone increased with $29 \%$ (EM), 37\% (IM), 44\% (PM) and 24\% (UM) and for the active metabolite with 36\% (EM), 37\% (IM), 35\% (PM) and 35\% (UM). In practice, the predicted active moiety of EM $(1 \mathrm{mg}$ twice a day) will increase by the amount of $17.4 \mu \mathrm{g} / \mathrm{L}$ (young adults) to $23.2 \mu \mathrm{g} / \mathrm{L}$ (oldest-old), leading to an increase of $33.6 \%$ during steady-state. These shift in $\mathrm{C}_{\max }$ values is also seen in the predicted populations of young-olds $(7.54 \%$ for $\mathrm{EM})$ and the medium-olds (18.7\% for EM) compared to the young adults. The predicted AUC of the oldest-old population showed the highest predicted change with up to a 1.52fold difference (range: 1.47 to 1.52 according to the different phenotypes) for risperidone and up to 1.39-fold difference (range: 1.34 to 1.39 ) for 9-hydroxyrisperidone compared to the young adults (Table 3). Overall, the AUC increased with age in all types of CYP2D6 metabolizers (Table 3). In contrast to the $\mathrm{C}_{\max }$ and $\mathrm{AUC}$, the $\mathrm{PK}$ parameter $\mathrm{t}_{\max }$ did not change with advanced age, neither for the parent drug, nor for the active metabolite (Table 3). The terminal half -life time showed predominantly an increase for the parent drug while aging, compared to the prediction of the medium-old population and the oldest-old to the young adults. Here, CYP2D6 PM showed the highest change with up to a 1.10-fold 
Table 3 Overview of different pharmacokinetics values for risperidone and 9-hydroxyrisperidone between different age groups: young adults ( 8 -35 years), young-olds (65-74 years), medium-olds (75-84 years), and oldest-old (85-100 years). EM: extensive metabolizer; IM: intermediate metabolizer; PM: poor metabolizer; UM: ultra-rapid metabolizer

\begin{tabular}{|c|c|c|c|c|c|c|c|}
\hline & & \multicolumn{3}{|l|}{ Risperidone } & \multicolumn{3}{|c|}{ 9-hydroxyrisperidone } \\
\hline & & $\begin{array}{l}\text { Ratio young-old/ } \\
\text { young adults }\end{array}$ & $\begin{array}{l}\text { Ratio medium-old/ } \\
\text { young adults }\end{array}$ & $\begin{array}{l}\text { Ratio oldest-old/ } \\
\text { young adults }\end{array}$ & $\begin{array}{l}\text { Ratio young-old/ } \\
\text { young adults }\end{array}$ & $\begin{array}{l}\text { Ratio medium-old/ } \\
\text { young adults }\end{array}$ & $\begin{array}{l}\text { Ratio oldest-old/ } \\
\text { young adults }\end{array}$ \\
\hline \multirow{4}{*}{$\begin{array}{l}\mathrm{AUC} \\
\qquad\left(\mu g^{*} \mathrm{~h} / \mathrm{l}\right)\end{array}$} & EM & 1.20 & 1.38 & 1.49 & 1.09 & 1.22 & 1.39 \\
\hline & $\mathbb{M}$ & 1.20 & 1.37 & 1.51 & 1.09 & 1.21 & 1.38 \\
\hline & PM & 1.21 & 1.36 & 1.52 & 1.15 & 1.18 & 1.34 \\
\hline & UM & 1.19 & 1.38 & 1.47 & 1.09 & 1.21 & 1.39 \\
\hline \multirow{4}{*}{$\begin{array}{l}\mathrm{C}_{\max } \\
\quad(\mu g / \mathrm{L})\end{array}$} & EM & 1.08 & 1.19 & 1.29 & 1.07 & 1.18 & 1.36 \\
\hline & $\mathbb{M}$ & 1.12 & 1.24 & 1.37 & 1.08 & 1.19 & 1.37 \\
\hline & PM & 1.17 & 1.29 & 1.44 & 1.07 & 1.18 & 1.35 \\
\hline & UM & 1.06 & 1.16 & 1.24 & 1.07 & 1.18 & 1.35 \\
\hline \multirow[t]{4}{*}{$t_{\max }(h)$} & EM & 1.00 & 1.00 & 1.00 & 1.00 & 1.00 & 1.00 \\
\hline & IM & 1.00 & 1.00 & 1.00 & 1.00 & 1.00 & 1.00 \\
\hline & PM & 1.00 & 1.00 & 1.00 & 1.00 & 1.00 & 1.00 \\
\hline & UM & 1.09 & 1.09 & 1.09 & 1.00 & 1.00 & 1.00 \\
\hline \multirow[t]{4}{*}{$t_{1 / 2}(h)$} & EM & 1,09 & 1,15 & 1,14 & 1,04 & 1,04 & 1,03 \\
\hline & IM & ।,07 & I, I I & 1,11 & 1,04 & 1,02 & I,00 \\
\hline & PM & I,08 & 1,10 & 1,10 & 0,98 & 0,85 & 0,74 \\
\hline & UM & 1,10 & 1,17 & 1,16 & 1,04 & 1,04 & 1,04 \\
\hline
\end{tabular}

difference resulting in a predicted $\mathrm{t}_{1 / 2}$ value of $19.4 \mathrm{~h}$ for the drug. For 9-hydroxyrisperidone $t_{1 / 2}$ was independent of age. Plasma concentration-time curve profiles of all types of CYP2D6 metabolizers are provided in Figs. 3, 4, 5 and 6.

\section{DISCUSSION}

In the present study, we analyzed the influence of age-related as well as CYP2D6- and CYP3A4- related physiological changes on the PK of risperidone and 9-hydroxyrisperidone using a PBPK approach. The application of calculated metabolic ratio and changes of $\mathrm{PK}$ values for dosage calculation in the elderly were the focus of the investigations.

\section{PBPK-Based Phenotyping Using Metabolic Ratio}

In our study, calculated risperidone/9-hydroxyrisperidone ratio were observed to readily predict CYP2D6 phenotypes of geriatric inpatients using a PBPK approach. Here, modelling based phenotyping was successful in 13 out of 17 geriatric inpatient using metabolic ratio (Fig. 1). The remaining four inpatients showed higher deviations between the observed and predicted plasma concentrations. There are manifold reasons for this. Firstly, all geriatric inpatients enrolled in the published investigation were treated under naturalistic conditions (29). This means, potentially concomitant medication with CYP inhibitors or inducers should be considered, since patients over the age of 65 years often suffer from several diseases. In general, it is known that a CYP2D6 PM is associated with an increase in moderateto-marked ADR and increased discontinuation due to ADR (34). A metabolic ratio of 3.39, as calculated in one out of the four geriatric inpatients (patient no. 15), indicate a potential CYP2D6 PM phenotype or the influence of a powerful CYP2D6 inhibitor (such as fluoxetine, paroxetine, or bupropion) (34). It is known that patients on strong inhibitors, the enzyme activity score of CYP2D6 is adjusted to 0 and the predicted phenotype is that of a PM (35). In addition, weak or moderate inhibitors leading to a multiplication of the activity score by $0.5(36,37)$. Next to the genetic aspects, it is secondly necessary to integrate individual covariates such as illness, especially renal and hepatic impairment into CYP genotyping process. Here, the creatinine clearance of two out of the four geriatric inpatients (patient no. 9 and 15 ) amounts to $25.0 \mathrm{~mL} / \mathrm{min} / 1.73 \mathrm{~m}^{2}$ and $27.5 \mathrm{~mL} / \mathrm{min} / 1.73 \mathrm{~m}^{2}$ using $8 \mathrm{~h}$ urine collection according to Maxwell et al. (29). Apart from an inadequate measurement, both values indicate a severe decrease in glomerular filtration rate (38).

Overall, the new approach demonstrates, that it is possible to determine CYP2D6 phenotypes in the elderly, only with the aid of measured plasma concentrations in combination with the extrapolated PBPK models. This new CYP2D6 


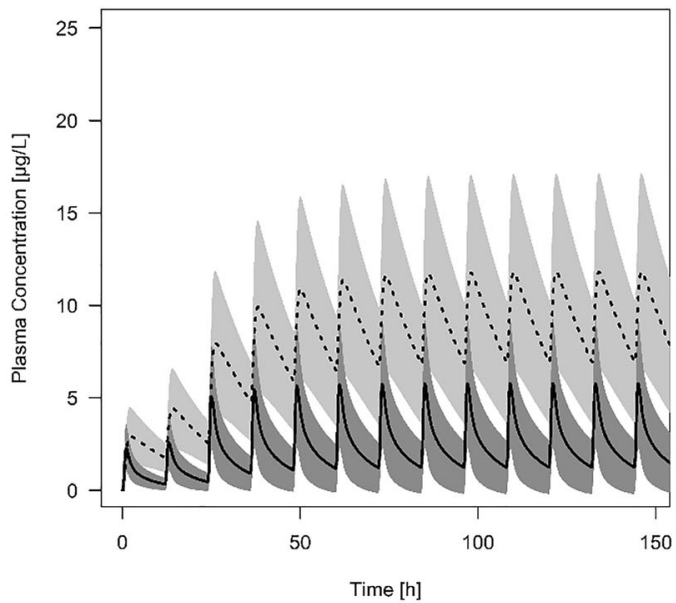

C

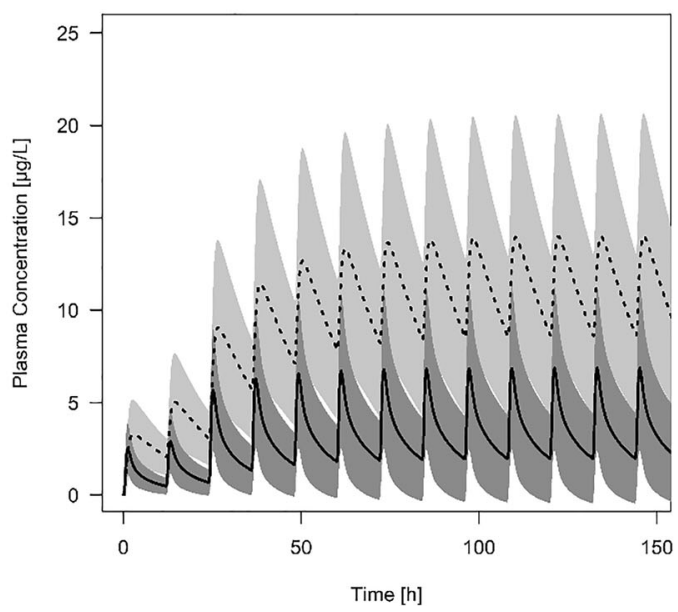

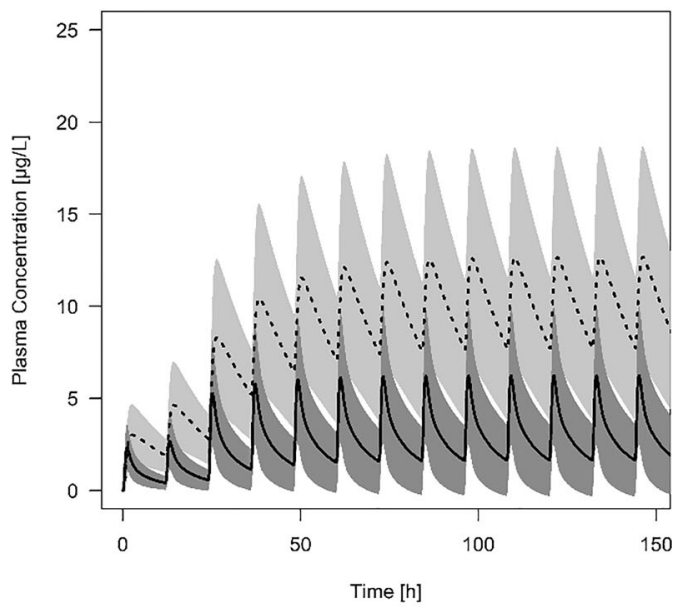

d

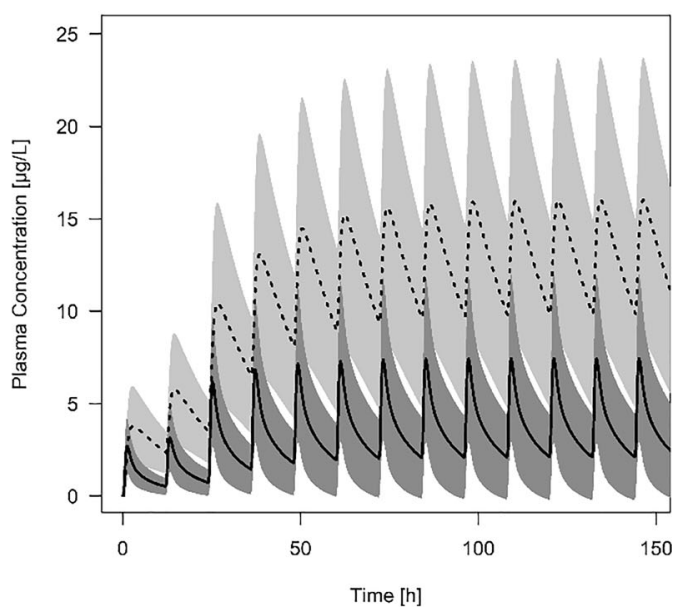

Fig. 3 Predicted plasma concentration-time curve profiles (mean and standard deviation) of risperidone (solid line) and 9-hydroxyrisperidone (dashed line) during aging for CYP2D6 extensive metabolizers. Simulations were performed starting with $0.5 \mathrm{mg}$ twice a day for I day, resulting in a dose increase up to I mg twice a day. a young adults ( $18-35$ years). b young-olds (65-74 years). c medium-olds (75-84 years). d oldest-old (85-100 years)

phenotyping approach is particularly accomplishable during therapeutic drug monitoring (TDM). A TDM of risperidone and its active metabolite is recommended by many experts because schizophrenia patients often fail to take medication, deviate from the prescribed regimen, or discontinue therapy prematurely $(17,39)$. This also occurs increasingly in the elderly, in whom we could identify age-related changes in the PK of risperidone. The combination of TDM and CYP2D6 phenotyping may be moving to clinical practice to improve safety (ADR) and efficacy (non-response) of pharmacotherapy of risperidone $(22,40)$. Moreover, pharmacogenetic testing, such as the use of metabolic ratio in combination with PBPK modelling, will improve the sensitivity and specificity of conventional drug monitoring by identifying patients showing conspicuous plasma concentrations. The advantage of that PBPK-based phenotyping approach over the standardized CYP genotyping is, that only plasma concentrations of the drug and its active metabolite are needed and no costly CYP genotyping has to be organized. The simple and very quick calculation of the metabolic ratio can be conducted easily by a clinician or other healthcare personnel. Long latency for laboratory results are no longer necessary. In addition, this method determines the phenotype of every schizophrenia patient and not only in patients suspected of altered CYP2D6 gene expression, as done for CYP genotyping. This leads to the fact that PBPK-based phenotyping using metabolic ratio also includes patients for whom a change in the CYP2D6 gene expression was accidentally identified. Even subpopulations like the elderly would benefit from that application. Altogether, when plasma concentrations of risperidone and 9-hydroxyrisperidone are available, e.g. during TDM, the new approach could be used to identify potential CYP2D6 


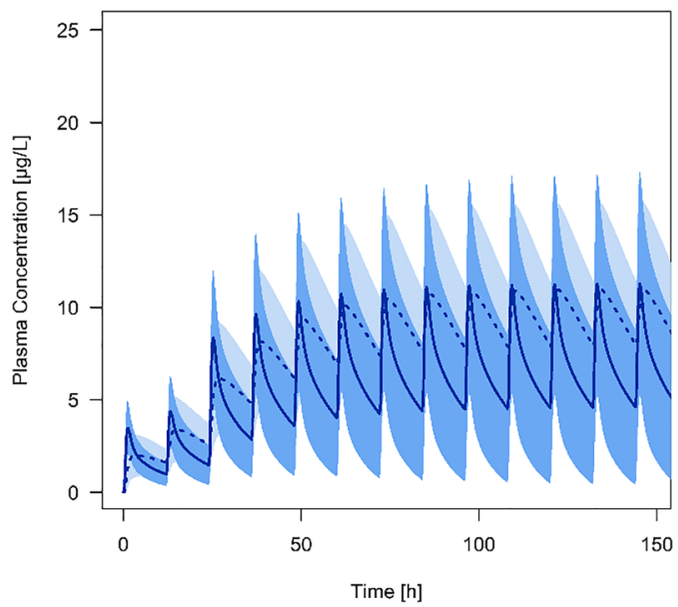

C

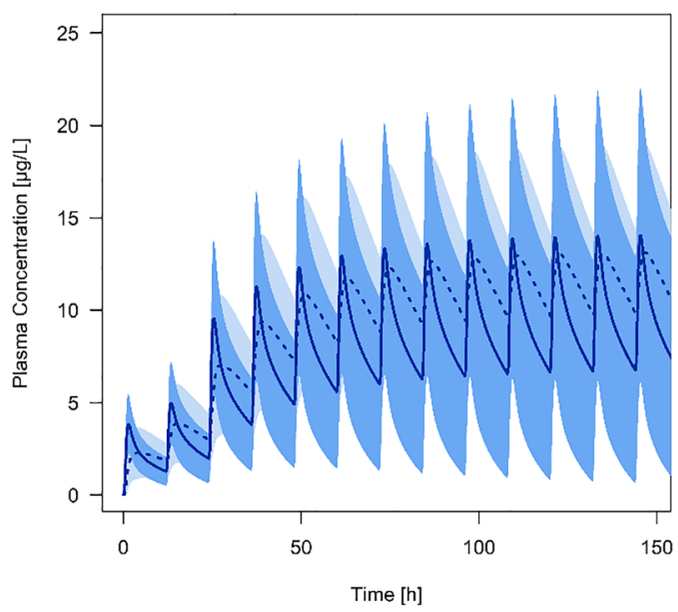

b

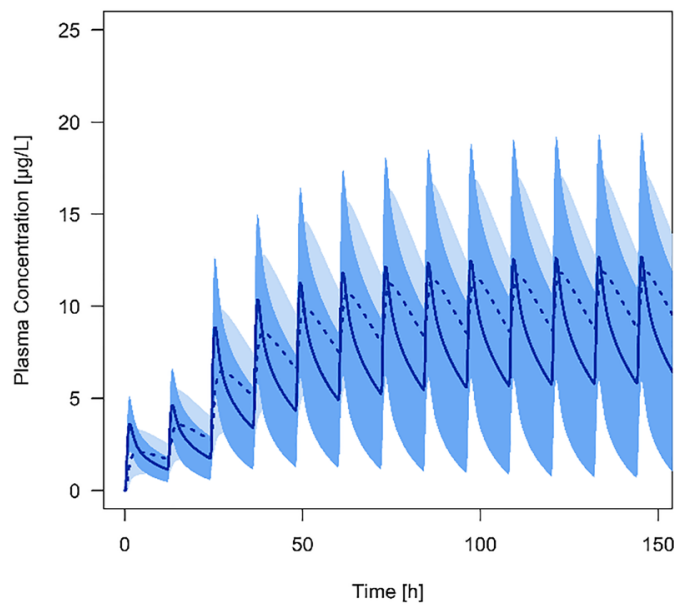

d

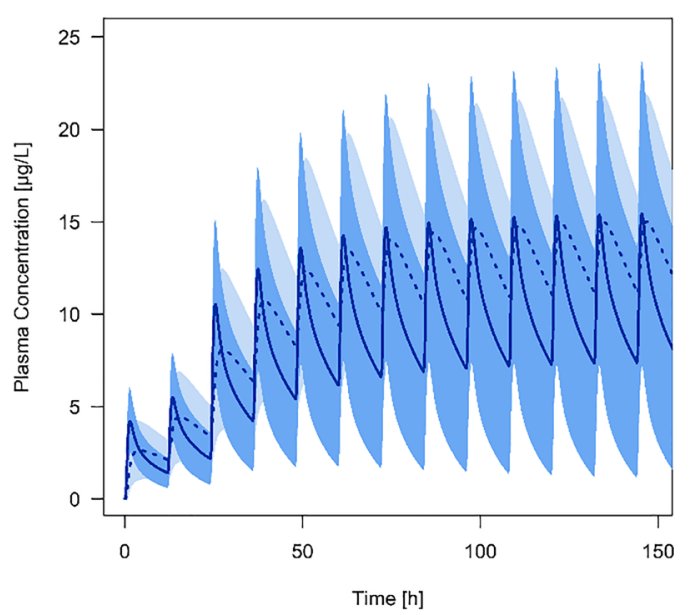

Fig. 4 Predicted plasma concentration-time curve profiles (mean and standard deviation) of risperidone (solid line) and 9-hydroxyrisperidone (dashed line) during aging for CYP2D6 intermediate metabolizers. Simulations were performed starting with $0.5 \mathrm{mg}$ twice a day for I day, resulting in a dose increase up to I mg twice a day. a young adults ( $18-35$ years). b young-olds (65-74 years). c medium-olds (75-84 years). d oldest-old (85-1 00 years)

UM, IM or PM and predict their individual dosage regimen with the help of PBPK modelling. This would be particularly important in the elderly ( $>65$ years) due to age-related changes in the $\mathrm{PK}$ of risperidone.

\section{Pharmacokinetic Changes in the Elderly}

The results of the present study show that steady-state plasma concentrations of risperidone and 9 hydroxyrisperidone including the active moiety increase progressively during aging (Figs. 3, 4, 5 and 6). Since CYP2D6 activity does not change with age, higher plasma concentrations in the elderly may be due to physiological changes, like a decrease in renal and hepatic function (15). This stems in part from findings of a general accumulation of antidepressant drug's active hydroxylated metabolites (e.g. nortriptyline and bupropion) in the elderly supposed by Pollock and colleagues (28). However, human in vitro and in vivo investigations do not uniformly support an agerelated decline in hepatic drug metabolism (41-43). It has been found that the PK of the two drugs nortriptyline and desipramine in the elderly is similar to those in younger patients (44). Apart from that, our findings are basically in line with the previous study $(28,45)$. The explanation for an accumulation of 9-hydroxyrisperidone after oral administration of risperidone may be the age-dependent decline in kidney function, leading to an increase in the exposure of the overall active moiety $\left(\mathrm{C}_{\max }\right.$ of young adults versus oldest-old $+33.6 \%$ for $\mathrm{EM})$. As a consequence, geriatric patients might be at increased risk of side effects when exposed to orally administrated risperidone. Based on the predicted higher plasma concentrations in all types of CYP2D6 metabolizers, a reduced daily dosing should be considered in the elderly. In clinical practice, it is therefore 


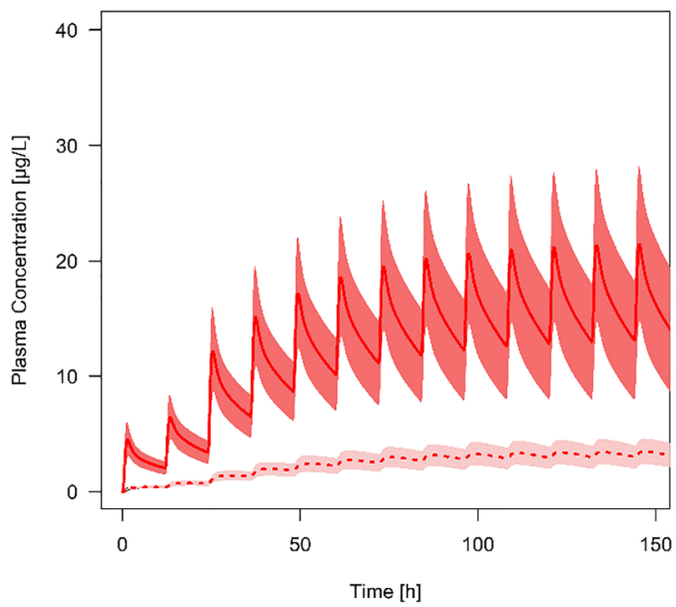

C

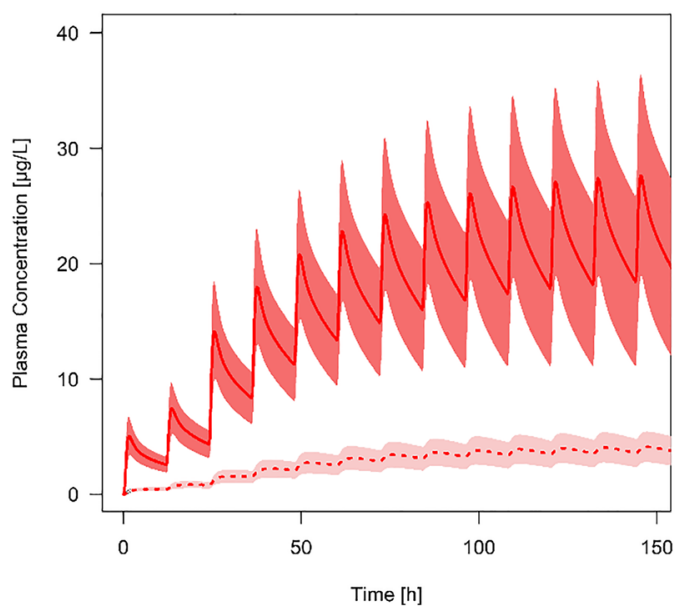

b

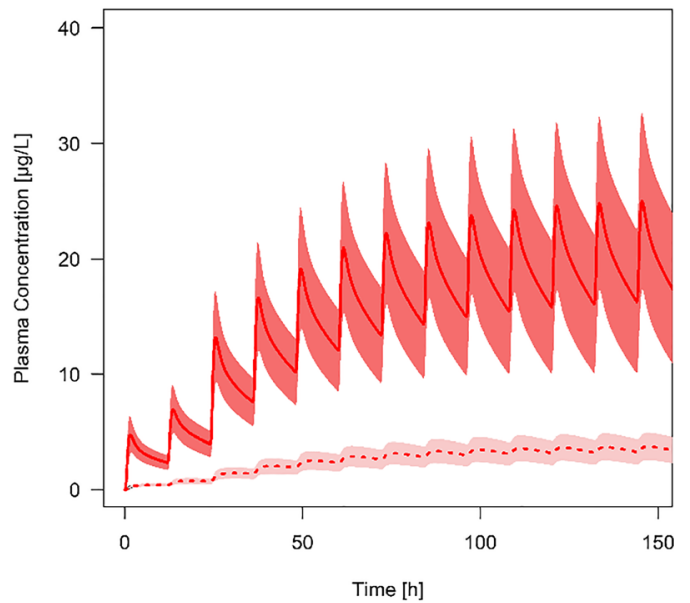

d

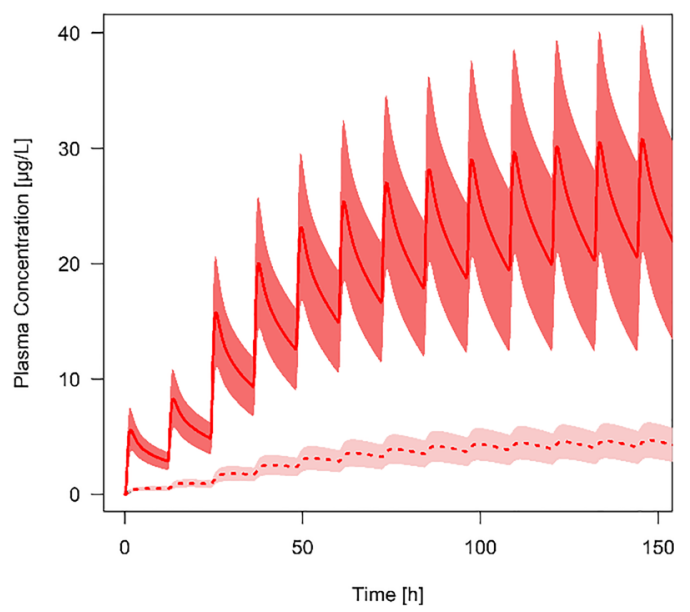

Fig. 5 Predicted plasma concentration-time curve profiles (mean and standard deviation) of risperidone (solid line) and 9-hydroxyrisperidone (dashed line) during aging for CYP2D6 poor metabolizers. Simulations were performed starting with $0.5 \mathrm{mg}$ twice a day for one day, resulting in a dose increase up to I mg twice a day. a young adults ( $18-35$ years). b young-olds (65-74 years). c medium-olds (75-84 years). d oldest-old (85-1 00 years)

important to be aware that daily oral dosing of risperidone generally needs to be lowered by more than $50 \%$ to achieve reduced treatment intensity in the oldest patients (3). These observations are in accordance with our developed PBPK models of the different age groups (Fig. 3, 4, 5 and 6). It is recognizable, that dose adjustment for the elderly compared to young adults should be conducted. Here, an accurate TDM, especially for geriatric inpatients showing a metabolic ratio $>1$, is highly recommended due to higher plasma concentrations, leading to a higher risk of ADR (Fig. 5) (40). For those patients it is appropriate to identify a potential CYP2D6 PM status via genotyping to avoid supratherapeutic plasma concentrations. Besides higher plasma concentrations, patients above 65 years show a longer elimination $t_{1 / 2}$ of risperidone compared to young adults. For PM the PK parameter $t_{1 / 2}$ amounts to $19.4 \mathrm{~h}$ for risperidone, which is consistent with previously published studies ( $\mathrm{t}_{1 / 2}$ of risperidone: $20 \mathrm{~h}$ ) (46). In accordance with the prolonged elimination half-life, Snoeck et al. supposed an enlarged AUC in the elderly compared to those of young adults for risperidone as well as for 9hydroxyrisperidone (46). The AUG was predicted to increase progressively with age in all types of metabolizers for both, the drug and its metabolite (Table 3), which can mainly explained by a diminished creatinine clearance and decreased renal clearance during aging (46). Overall, the new investigations illustrate on the one hand age-related changes in the PK of the drug and its active metabolite. One the other hand the PK-based PBPK models also showed that an age-appropriate dosing of risperidone is essential for a successful therapy. Thus, in patients over the age of 65 years, dose reduction for all types of 
a

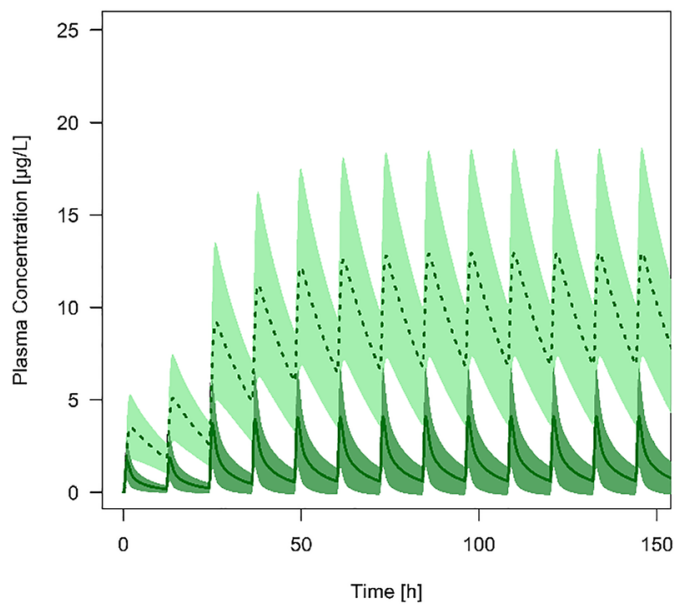

C

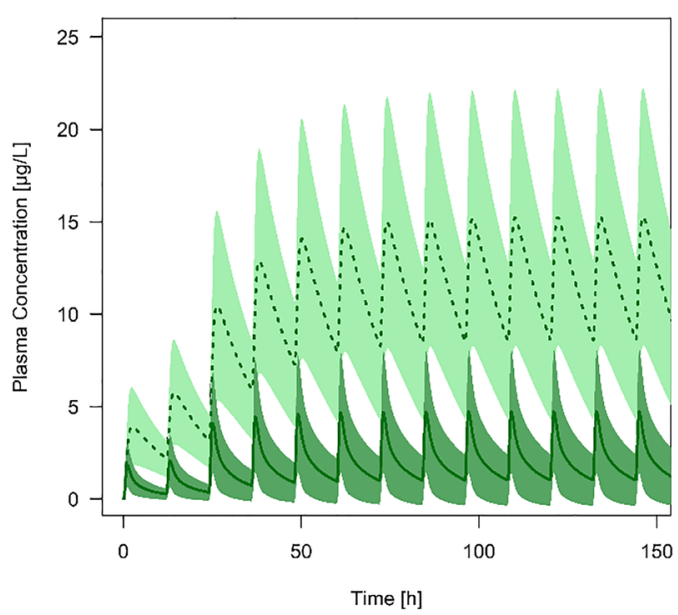

b

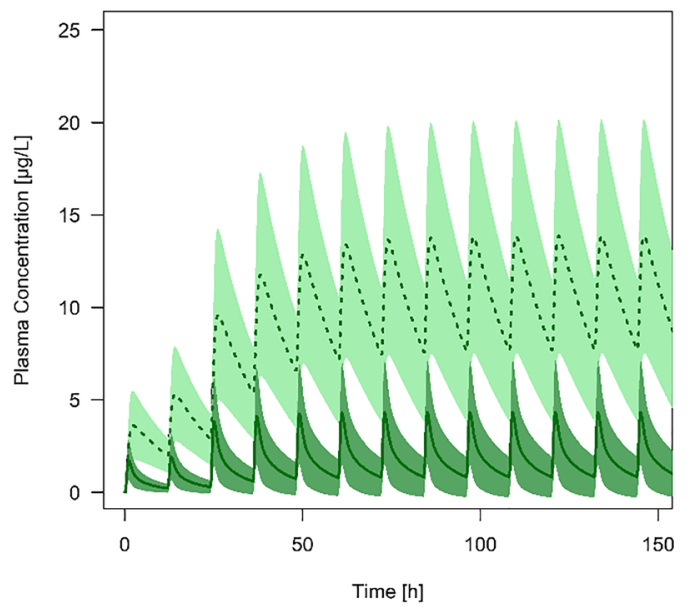

d

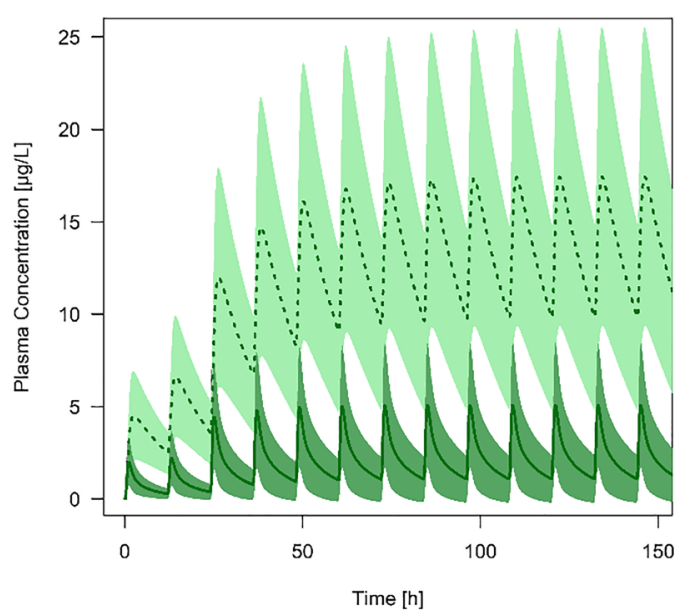

Fig. 6 Predicted plasma concentration-time curve profiles (mean and standard deviation) of risperidone (solid line) and 9-hydroxyrisperidone (dashed line) during aging for CYP2D6 ultra-rapid metabolizers. Simulations were performed starting with $0.5 \mathrm{mg}$ twice a day for one day, resulting in a dose increase up to I mg twice a day. a young adults ( $18-35$ years). b young-olds (65-74 years). c medium-olds (75-84 years). d oldest-old (85- 00 years)

metabolizers should be considered based on the current findings in order to avoid supratherapeutic plasma concentrations.

\section{Impact of Age on the Pharmacodynamics}

Finally, it should be mentioned that age-related changes in the physiology and biology of the elderly also affect the pharmacodynamics (PD) of drugs. Although risperidone has a linear concentration side-effect profile in the elderly, neuronal changes such as a decrease in dopamine or acetylcholine can lead to greater sensitivity of dopamine receptor D2 antagonists and antimuscarinic agents (47). Thus, the predicted higher plasma concentrations of risperidone and 9hydroxyrisperidone may lead to a more relevant impact on the PD of the elderly compared to young adults. In contrast to that, the impact of different CYP2D6 metabolizers on the PD is not clear.

\section{Limitation}

A clear limitation of our study is that clinical PK data for genotyped individuals aged older than 65 years are sparse and thus, the conducted prediction and simulation results need to be interpreted with caution. For the observed data used in our study, no prior CYP genotyping was performed, so phenotyping was only based on calculated metabolic ratio. In addition, several individual data were not provided regarding potential liver cirrhosis (48), renal impairment (49), heart disease (50) or concomitant medication (51) of each geriatric patient, which would be helpful for modelling. It is known that those patient related circumstances can change physiology, 
resulting in a variation of individual PK. Finally, a PK/PD model especially for patients above the age of 65 years would be helpful to understand the impact of age-related changes, resulting in an optimization of the individualised treatment strategy in the elderly according to CYP2D6 phenotype.

\section{CONCLUSION}

The present study generated and verified a PBPK model for risperidone and 9-hydroxyrisperidone for different CYP2D6 metabolizers over the age of 65 years. After oral administration of risperidone, a progressive increase in the predicted plasma concentrations of risperidone and its active metabolite 9-hydroxyrisperidone was observed while aging. Although the prescribed dosage is generally lower in geriatric patients, a close TDM of both risperidone and 9-hydroxyrisperidone is highly recommended for all types of CYP2D6 metabolizers. As part of the TDM, CYP2D6 phenotyping by calculating the metabolic ratio in combination with PBPK modelling should be considered, on the one hand to identify patients who show changes in their GYP2D6 gene expression, and on the other hand to predict the individual dosing regimen. Overall, using this new approach, the identification of potential CYP2D6 $\mathrm{PM}$, IM, or UM is cheaper, faster and easier compared to conventional CYP genotyping and can be used to improve patient's safety and ensure the best therapy for each patient over the age of 65 years.

ACKNOWLEDGMENTS AND DISCLOSURES. Lisa Alina Kneller and Georg Hempel have no potential conflicts of interest to declare.

\section{FUNDING INFORMATION}

Open Access funding provided by Projekt DEAL.

Open Access This article is licensed under a Creative Commons Attribution 4.0 International License, which permits use, sharing, adaptation, distribution and reproduction in any medium or format, as long as you give appropriate credit to the original author(s) and the source, provide a link to the Creative Commons licence, and indicate if changes were made. The images or other third party material in this article are included in the article's Creative Commons licence, unless indicated otherwise in a credit line to the material. If material is not included in the article's Creative Commons licence and your intended use is not permitted by statutory regulation or exceeds the permitted use, you will need to obtain permission directly from the copyright holder. To view a copy of this licence, visit http://creativecommons.org/licenses/by/4.0/.

\section{REFERENCES}

1. UN DESA. Anteil von Stadt- und Landbewohnern in Deutschland von 1990 bis 2015 und Prognose bis 2050. Statista. 2019. https:// de.statista.com/statistik/daten/studie/167166/umfrage/ prognose-des-bewohneranteils-nach-wohnstandort-seit-1990/. Accessed 8 Oct 2019

2. World Bank Group. Population ages 65 and above (\% of total population). 2019. https://data.worldbank.org/indicator/SP. POP.65UP.TO.ZS?locations=DE. Accessed 8 Oct 2019.

3. Molden E, Waade RB, Hoff M, Haslemo T. Impact of ageing on serum concentrations of Risperidone and its active metabolite in patients with known CYP2D6 genotype. Basic Clin Pharmacol Toxicol. 2016;119:470-5. https://doi.org/10.1111/bcpt.12614 .

4. Ryan Bailey. Applied clinical trials. 2018. http://www. appliedclinicaltrialsonline.com/importance-age-diversity-clinicaltrials. Accessed 8 Oct 2019.

5. Dunnill MS, Halley W. Some observations on the quantitative anatomy of the kidney. J Pathol. 1973;110:113-21. https://doi. org/10.1002/path.1711100202

6. Hollenberg NK, Adams DF, Solomon HS, Rashid A, Abrams HL, Merrill JP. Senescence and the renal vasculature in normal man. Circ Res. 1974;34:309-16. https://doi.org/10.1161/01.res.34.3. 309 .

7. Cockcroft DW, Gault MH. Prediction of creatinine clearance from serum creatinine. Nephron. 1976;16:31-41. https://doi.org/10. 1159/000180580 .

8. Koff RS, Garvey AJ, Burney SW, Bell B. Absence of an age effect on sulfobromophthalein retention in healthy men. Gastroenterology. 1973;65:300-2.

9. Marchesini G, Bua V, Brunori A, Bianchi G, Pisi P, Fabbri A, et al. Galactose elimination capacity and liver volume in aging man. Hepatology. 1988;8:1079-83. https://doi.org/10.1002/hep. 1840080516 .

10. Wynne HA, Cope LH, Mutch E, Rawlins MD, Woodhouse KW, James OF. The effect of age upon liver volume and apparent liver blood flow in healthy man. Hepatology. 1989;9:297-301. https:// doi.org/10.1002/hep.1840090222 .

11. Kinirons MT, Crome P. Clinical pharmacokinetic considerations in the elderly. An update. Clin Pharmacokinet. 1997;33:302-12. https://doi.org/10.2165/00003088-199733040-00005 .

12. Huang M, Shen-Tu J, Hu X, Chen J, Liu J, Wu L. Comparative fasting bioavailability of dispersible and conventional tablets of risperidone: a single-dose, randomized-sequence, open-label, twoperiod crossover study in healthy male Chinese volunteers. Clin Ther. 2012;34:1432-9. https://doi.org/10.1016/j.clinthera.2012. 04.027 .

13. Fang J, Bourin M, Baker GB. Metabolism of risperidone to 9hydroxyrisperidone by human cytochromes P450 2D6 and 3A4. Naunyn Schmiedeberg's Arch Pharmacol. 1999;359:147-51.

14. Yasui-Furukori N, Saito M, Nakagami T, Furukori H, Suzuki A, Kondo T, et al. Clinical response to risperidone in relation to plasma drug concentrations in acutely exacerbated schizophrenic patients. J Psychopharmacol (Oxford). 2010;24:987-94. https:// doi.org/10.1177/0269881109104849.

15. Shulman RW, Ozdemir V. Psychotropic medications and cytochrome P450 2D6: pharmacokinetic considerations in the elderly. Can J Psychiatr. 1997;42(Suppl 1):4S-9S.

16. Feng Y, Pollock BG, Coley K, Marder S, Miller D, Kirshner M, et al. Population pharmacokinetic analysis for risperidone using highly sparse sampling measurements from the CATIE study. Br J Clin Pharmacol. 2008;66:629-39. https://doi.org/10.1111/j. 1365-2125.2008.03276.x . 
17. Hiemke G, Bergemann N, Glement HW, Conca A, Deckert J, Domschke K, et al. Consensus guidelines for therapeutic drug monitoring in Neuropsychopharmacology: update 2017. Pharmacopsychiatry. 2017;51:9-62. https://doi.org/10.1055/s0043-116492

18. Chouinard G, Jones B, Remington G, Bloom D, Addington D, MacEwan GW, et al. A Canadian multicenter placebo-controlled study of fixed doses of risperidone and haloperidol in the treatment of chronic schizophrenic patients. J Clin Psychopharmacol. 1993;13:25-40.

19. Gareri P, Segura-García C, Manfredi VGL, Bruni A, Ciambrone $\mathrm{P}$, Cerminara G, et al. Use of atypical antipsychotics in the elderly: a clinical review. Clin Interv Aging. 2014;9:1363-73. https://doi. org/10.2147/CIA.S63942 .

20. Puangpetch A, Vanwong N, Nuntamool N, Hongkaew Y, Chamnanphon M, Sukasem C. CYP2D6 polymorphisms and their influence on risperidone treatment. Pharmgenomics Pers Med. 2016;9:131-47. https://doi.org/10.2147/PGPM. S107772.

21. Gaedigk A, Simon SD, Pearce RE, Bradford LD, Kennedy MJ, Leeder JS. The CYP2D6 activity score: translating genotype information into a qualitative measure of phenotype. Clin Pharmacol Ther. 2008;83:234-42. https://doi.org/10.1038/ sj.clpt.6100406.

22. Kneller LA, Abad-Santos F, Hempel G. Physiologically based pharmacokinetic Modelling to describe the pharmacokinetics of Risperidone and 9-Hydroxyrisperidone according to cytochrome P450 2D6 phenotypes. Glin Pharmacokinet. 2020;59:51-65. https://doi.org/10.1007/s40262-019-00793-x .

23. Open Systems Pharmacology Suite. Open Systems Pharmacology Suite.

24. Open Systems Pharmacology Suite Community. Open Systems Pharmacology Suite Manual. 2017. https://www.google.com/ url? sa $=\mathrm{t} \& \mathrm{rct}=\mathrm{j} \& \mathrm{q}=\& \mathrm{esrc}=\mathrm{s} \& \operatorname{source}=\mathrm{web} \& \mathrm{~cd}=1 \& \mathrm{ved}=$ 2 a h U K E w j o g 9 C

$7 \mathrm{uPjAhUGzqQKHTuuAGAO \overline {Fj } A A e g Q I A R A C \& u r l = h t t p s} \%$ $3 \mathrm{~A} \% 2 \mathrm{~F} \% 2 \mathrm{~F} w \mathrm{ww}$.researchgate.net $\% 2$ Fprofile $\% 2$ FEngi_ Algharably $\% 2 \mathrm{Fpost} \% 2 \mathrm{FPKSim}-$ is there are manual available for_PKSim_MoBi_ca_anyone_share it_please $\% 2$ Fattachment $\%$ 2 F 5 a f 034 a 94 c de 260 d 15 d d 1 b f $3 \% 2$ F A S $\%$ 253A623609756258304\%25401525691560465\%2Fdownload $\%$ 2FOpen $\% 2 \mathrm{BSystems} \% 2 \mathrm{BPharmacology} \% 2 \mathrm{BSuite}$.pdf\&usg $=$ AOvVaw13CpyfmLFMc2yyqdfH6HA3. Accessed 10 Oct 2019.

25. Willmann S, Lippert J, Sevestre M, Solodenko J, Fois F, Schmitt W. PK-Sim $®$ : a physiologically based pharmacokinetic 'whole-body' model. BIOSILICO. 2003;1:121-4. https://doi.org/10.1016/ S1478-5382(03)02342-4 .

26. Kuepfer L, Niederalt C, Wendl T, Schlender J-F, Willmann S, Lippert J, et al. Applied concepts in PBPK modeling: how to build a PBPK/PD model. CPT Pharmacometrics Syst Pharmacol. 2016;5:516-31. https://doi.org/10.1002/psp4.12134 .

27. Schlender J-F, Meyer M, Thelen K, Krauss M, Willmann S, Eissing $\mathrm{T}$, et al. Development of a whole-body physiologically based pharmacokinetic approach to assess the pharmacokinetics of drugs in elderly individuals. Clin Pharmacokinet. 2016;55:1573-89. https://doi.org/10.1007/s40262-016-0422-3

28. Pollock B, Forsyth G, Bies R. The critical role of clinical pharmacology in geriatric psychopharmacology. Clin Pharmacol Ther. 2009;85:89-93. https://doi.org/10.1038/clpt.2008.229 .

29. Maxwell RA, Sweet RA, Mulsant BH, Rosen J, Kirshner MA, Kastango KB, et al. Risperidone and 9-hydroxyrisperidone concentrations are not dependent on age or creatinine clearance among elderly subjects. J Geriatr Psychiatry Neurol. 2002;15:7781. https://doi.org/10.1177/089198870201500205 .
30. Hamad Medical Corporation. Urine Collection Manual 20182020. https://www.hamad.qa/EN/Hospitals-and-services/ Hamad-General-Hospital/Hospital-Services/ClinicalDepartments/Documents/Urine $\% 20$ Collection $\% 20$ Procedure $\%$ 20\%20Manual $\% 20-\% 202018-2020-\% 20$ for $\% 201$ ab $\% 20$ guide. pdf. Accessed 1 Oct 2019.

31. Singapore Department of Statistics. National Statistical Standards. 2016. https://www.singstat.gov.sg/-/media/files/standards_and classifications/nsa.pdf. Accessed 10 Oct 2019.

32. European Medicines Agency. Guideline on the qualification and reporting of physiologically based pharmacokinetic (PBPK) modelling and simulation 21 July 2016. London.

33. R Development Core team. R: a language and environment for statistical computing. Vienna, Austria: R Foundation for statistical Computing; 2008.

34. de Leon J, Susce MT, Pan R-M, Fairchild M, Koch WH, Wedlund PJ. The CYP2D6 poor metabolizer phenotype may be associated with risperidone adverse drug reactions and discontinuation. J Clin Psychiatry. 2005;66:15-27. https://doi.org/10.4088/jcp. v66n0103 .

35. Crews KR, Gaedigk A, Dunnenberger HM, Leeder JS, Klein TE, Caudle KE, et al. Clinical Pharmacogenetics implementation consortium guidelines for cytochrome P450 2D6 genotype and codeine therapy: 2014 update. Clin Pharmacol Ther. 2014;95:376-82. https://doi.org/10.1038/clpt.2013.254

36. Borges S, Desta Z, Jin Y, Faouzi A, Robarge JD, Philips S, et al. Composite functional genetic and comedication CYP2D6 activity score in predicting tamoxifen drug exposure among breast cancer patients. J Clin Pharmacol. 2010;50:450-8. https://doi.org/10. 1177/0091270009359182

37. Borges S, Desta Z, Li L, Skaar TC, Ward BA, Nguyen A, et al. Quantitative effect of CYP2D6 genotype and inhibitors on tamoxifen metabolism: implication for optimization of breast cancer treatment. Clin Pharmacol Ther. 2006;80:61-74. https://doi.org/10. 1016/j.clpt.2006.03.013

38. National Kidney Foundation. K/DOQI clinical practice guidelines for chronic kidney disease: Evaluation, classification and stratification. Am J Kidney Dis. 2002:S1-S266.

39. Valenstein M, Copeland LA, Blow FC, McCarthy JF, Zeber JE, Gillon L, et al. Pharmacy data identify poorly adherent patients with schizophrenia at increased risk for admission. Med Care. 2002;40:630-9. https://doi.org/10.1097/00005650-20020800000002 .

40. Wilkinson GR. Drug metabolism and variability among patients in drug response. N Engl J Med. 2005;352:221 1-21. https://doi.org/ 10.1056/NEJMra032424.

41. Pollock BG, Perel JM, Altieri LP, Kirshner M, Fasiczka AL, Houck $\mathrm{PR}$, et al. Debrisoquine hydroxylation phenotyping in geriatric psychopharmacology. Psychopharmacol Bull. 1992;28:163-8.

42. Schmucker DL, Woodhouse KW, Wang RK, Wynne H, James $\mathrm{OF}, \mathrm{McManus} \mathrm{M}$, et al. Effects of age and gender on in vitro properties of human liver microsomal monooxygenases. Clin Pharmacol Ther. 1990;48:365-74. https://doi.org/10.1038/clpt.1990.164 .

43. Wynne HA, Mutch E, James OF, Wright P, Rawlins MD, Woodhouse KW. The effect of age upon the affinity of microsomal mono-oxygenase enzymes for substrate in human liver. Age Ageing. 1988;17:401-5. https://doi.org/10.1093/ageing/17.6. 401 .

44. von Moltke LL, Greenblatt DJ, Shader RI. Clinical pharmacokinetics of antidepressants in the elderly. Therapeutic implications. Clin Pharmacokinet. 1993;24:141-60. https://doi.org/10.2165/ 00003088-199324020-00004 .

45. Aichhorn W, Weiss U, Marksteiner J, Kemmler G, Walch T, Zernig $\mathrm{G}$, et al. Influence of age and gender on risperidone plasma 
concentrations. J Psychopharmacol (Oxford). 2005;19:395-401. https://doi.org/10.1177/0269881105053306 .

46. Snoeck E, van Peer A, Sack M, Horton M, Mannens G, Woestenborghs R, et al. Influence of age, renal and liver impairment on the pharmacokinetics of risperidone in man. Psychopharmacology. 1995;122:223-9.

47. Antonini A, Leenders KL, Reist H, Thomann R, Beer HF, Locher $\mathrm{J}$. Effect of age on D2 dopamine receptors in normal human brain measured by positron emission tomography and 11C-raclopride. Arch Neurol. 1993;50:474-80. https://doi.org/10.1001/ archneur.1993.00540050026010 .

48. Johnson TN, Boussery K, Rowland-Yeo K, Tucker GT, RostamiHodjegan A. A semi-mechanistic model to predict the effects of liver cirrhosis on drug clearance. Clin Pharmacokinet. 2010;49: 189-206. https://doi.org/10.2165/11318160-000000000-00000 .
49. Rowland Yeo K, Aarabi M, Jamei M, Rostami-Hodjegan A. Modeling and predicting drug pharmacokinetics in patients with renal impairment. Expert Rev Clin Pharmacol. 2011;4:261-74. https://doi.org/10.1586/ecp.10.143 .

50. Rodighiero V. Effects of cardiovascular disease on pharmacokinetics. Cardiovasc Drugs Ther. 1989;3:711-30. https://doi.org/10. 1007/bf01857622 .

51. European Medicines Agency. Guideline on the investigation of drug interactions. 2012. https://www.ema.europa.eu/en/ documents/scientific-guideline/guideline-investigation-druginteractions en.pdf. Accessed 16 Oct 2019.

Publisher's Note Springer Nature remains neutral with regard to jurisdictional claims in published maps and institutional affliations. 